\title{
Architectural design education: in varietate unitas
}

\author{
E. J. G. C. van Dooren ${ }^{1}$ - J. van Merriënboer ${ }^{2}$. \\ H. P. A. Boshuizen ${ }^{3} \cdot$ M. van Dorst ${ }^{1}$ - M. F. Asselbergs ${ }^{1}$
}

Accepted: 4 January 2017/Published online: 13 February 2017

(C) The Author(s) 2017. This article is published with open access at Springerlink.com

\begin{abstract}
A fascinating and rich landscape of personal views and approaches can be seen in architectural design and in architectural design education. This variation may be confusing for students. This paper focuses on the question: is the framework of generic elements that we developed for explicating the design process helpful to compare the differences in architectural design approaches? The results of interviewing a variety of 15 architectural, urban and landscape designers show all kinds of personal approaches that have a set of five underlying generic elements in common. Therefore, the framework may be helpful for teachers and students to describe these personal approaches and may help students in understanding differences and similarities and in finding out what their own personal approach may be.
\end{abstract}

Keywords Design process - Design education · Design strategy · Design methods · Architectural design

\section{Introduction}

Architecture students are confronted with a lot of different design views and approaches. Hector Guimard used the shapes of flowers in his designs for entrances to the metro stations in Paris. Eero Saarinen shaped the terminal for JFK International airport New York like a bird ready to fly away.

\section{E. J. G. C. van Dooren \\ E.J.G.C.vanDooren@tudelft.nl}

1 Faculty of Architecture and the Built Environment, Delft University of Technology, Julianalaan 134, 2628 BL Delft, The Netherlands

2 Department of Educational Development and Research, Maastricht University, PO Box 616, 6200 MD Maastricht, The Netherlands

3 Open University, Valkenburgerweg 177, 6419 AT Heerlen, The Netherlands 
Berlage, Le Corbusier and Richard Meijer worked with proportional systems and geometrical grids. Wassily Kandinsky, Paul Klee and Steven Holl translated musical compositions and sounds into visual, spatial and architectural configurations. Rem Koolhaas used montage to combine programmatic elements and quoted other architects in his work. Coop Himmelb(l)au created a formal configuration based on an explosive-like sketch, drawn with eyes closed. Aldo Rossi used meaningful spatial types. Venturi deliberately designed a composition with contradictory typologies. Hassan Fathy applied ancient construction methods in Egypt such as adobe. He also used traditional courtyards to provide passive cooling. Together reveal these examples (Jormakka 2008) a fascinating and rich landscape of design products and design approaches. In the words of Lawson and Dorst: "Designers all have their own unique backgrounds and collections of skills, attitudes, values and interests. Designers work on their own set of problems and circumstances" (2008, p. 18).

The same rich differentiation is recognised by Schön in architectural education: "practitioners have tended themselves with a bewildering array of contending schools, each of which has a claim to architecture" (1983, p. 78). He ascertains that for a student this is confusing: "Should we take them as competing definitions of the field, which entail very different concepts of professional knowledge and practice? Or as stylistic variations of a design process that is essentially the same for all schools?" (1983, p. 78).

How can teachers help students in this confusing array of personal design approaches?

There are different aspects related to this question. It might help when teachers of architecture (read designers) make their design approach explicit to students and, moreover, when they could compare their design approach to that of others. For comparing the different personal design approaches, it might help to make communication clear when there is some kind of conceptual framework or vocabulary describing an underlying generic process.

Schön (1983) answers his own question by considering the design process a generic process, describing it as a reflective conversation underlying the variety of architecture schools. Also others (Cross 2001, 2007; Darke 1979; Lawson 1994, 2006; Lawson and Dorst 2009) ascertain that beyond all personal differences and approaches there are underlying elements in the design process, which are essentially the same for all designers. Based on these underlying generalities, specific for the context of architectural design education, a framework has been developed with generic elements for making the design process explicit (van Dooren et al. 2014). Knowing by experience that expert designers (read teachers) are not used to making the design process explicit, the framework is meant for students and teachers in architecture to talk about the complex, personal, open-ended and creative design process and to give insight in the basic design activities.

The main aim of this paper is to explore whether this framework is suitable to characterise the differences between architectural designers-and consequently between teachers. Is the framework a useable tool for understanding and positioning the differences in architectural design approaches by recognizing them as personal views and expressions of generic underlying basic design elements?

To explore the feasibility of the framework in respect to making personal differences visible in relation to underlying generalities, expert designers were interviewed about their design approaches.

First the framework will be placed in the context of architectural and educational methods and approaches. Then the framework will be explained and the main research question and sub questions will be defined. In addition, information will be given about the research method. In the following section the results of the interviews are presented i.e. the personal architectural design approaches in relation to the framework of the generic 
elements. In the final section conclusions are drawn and the way teachers and students may benefit from the framework is discussed.

\section{Context}

Central in all architectural design education is the studio: students learn-by-doing, by practicing design tasks. The studio is mostly accompanied by additional courses about all kind of subjects, such as historical, compositional and technical knowledge. However, as mentioned earlier: a rich differentiation in architectural design education models can be seen. Three main perspectives or directions may be distinguished.

1. Architectural vision Architectural design education has traditionally been grounded (for almost three centuries) in an intuitive vision or idea of what architecture should be. It started with the Ecole des Beaux Arts and includes famous examples as the Ecole Polytechnique and the Bauhaus. Being professional designers, teachers come up with design assignments in the studio and a wide variety of knowledge in courses, based on the ideas they have about architecture and on how they themselves learned designing. Being designers, their focus is on the architectural content. In fact, education takes place on the level of the architectural debate. It is concerned with the cultural or personal view on 'good architecture'. As a result, these educational models and ways of tutoring take position in architecture, mostly in an implicit way.

2. Scientific and cognitive point of view Inspired by the successes in scientific disciplines, there has been (for roughly half a century) discussion, at least on a theoretical level, about the role of scientific knowledge in relation to architecture and more in particular in relation to the design process. The still ongoing debate can be summarised along two main streams, which Schön (1983) characterised as rational technology, related to a positivistic, objective science concept and reflective practice, related to a 'constructivistic' world view. According to Hillier et al. (1972), in the case of rational problem solving the design process proceeds by analysis and synthesis: scientific knowledge and rules should decrease the designer's reliance on intuition and rules of thumb and design methods must be systematised. In the case of reflective practice the design process proceeds by conjecture and analysis. Design problems are pre-structured by constraints and the designer's own cognitive map.

3. Educational point of view With the developments in educational science, the input from this science in architectural education has increased (for roughly the last decennia). In particular notions such as learning goals, assessment criteria, and curriculum design were used to help teachers (being professional designers) in making the design education more clearly structured and help students to understand what they should learn. Examples of general and concrete learning goals are the ability to create a design, the ability to acquire necessary information, the ability to weigh aspects, the ability to determine, structure and relate use and space, the ability to apply technical knowledge and the ability to choose and formulate criteria.

All architecture and design education models remain on the level of the architectural debate and on the level of discussions on the design product. In our opinion (van Dooren et al. 2014), to reduce the resulting confusion a generic conceptual vocabulary might help.

Before giving a short overview of the framework or vocabulary of the five generic elements, two remarks have to be made. First, the framework is specifically meant for use in design education as a generic underlying vocabulary of the architectural design process. This means that it should be usable in all kinds of situations, such as working as an 
individual designer or designing in a team. Second, the research in this paper focuses on architectural design, including urban and landscape design, but for reasons of readability, regularly the shorter notions 'designing' and 'design process' are used. Although the focus is on architectural design, at the same time, research on the design process (Cross 2001) and discussions in an interdisciplinary design education network (TU Delft) point out that the framework may be useful in other design disciplines as well.

\section{Framework}

The framework consists of five generic elements (see Fig. 1).

1. The design process is a process of experimenting, a fractal-like process of coming up with, testing and evaluating hypotheses, or a process of exploring and decision making by activities such as collecting information, analysing, abstracting, associating, comparing, evaluating, and taking distance. Designers present provisional solutions, they study all kinds of aspects in different options and they propose alternatives to compare what "fits best". After each trial, they reflect on intended and unintended consequences, in order to come up with new proposals.

2. In the process of experimenting a designer needs a focus, an inspiring direction, a guiding theme or qualities, something to hold on to in an almost endless field of possibilities and to give character and coherence to the design. Coming up with a guiding theme, may happen at the start or later on in the process of experimenting. Usually it happens in steps, in a "train of thought".

3. Designers experiment and come up with their guiding theme within and across all levels of scale and meaning or domains. For architecture five domains are defined: (a) space and composition, (b) material, climate and structure, (c) function and movement, (d) site, and (e) socio-cultural, historical, philosophical context. Designers come up with statements and make choices in all these domains, and within these domains they have to deal with a lot of criteria and information: such as government rules, personal preferences, client's wishes, "universal" laws, and cultural habits.

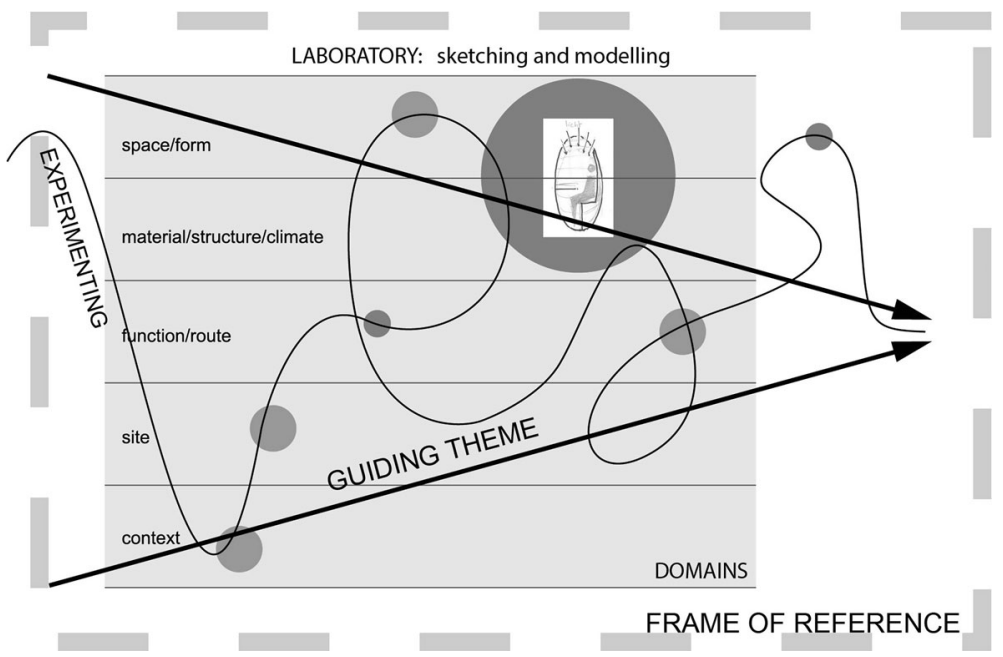

Fig. 1 The five generic elements in the design process: (1) experimenting, (2) guiding theme, (3) domains, (4) frame of reference and (5) laboratory (van Dooren et al. 2014) 
4. The process of experimenting and working with a guiding theme takes place in and with the help of a broader context, a frame of references or library. The knowledge about architectural designing is stored in the built environment and in theory. Designers build up a library, for unconscious and conscious use during the design process. In all domains, the knowledge is in the form of rules of thumb and in principles and patterns used, tested in the situation at hand, rejected, transformed, and so on.

5. A laboratory is needed for experimenting. The "designerly language" of sketching and modelling functions as an extended working memory. By making visual and explicit, the process of "designerly" thinking, of making choices, formulating, reformulating, evaluating, exploring possibilities and discovering new insights, unfolds.

This paper focuses on the question: Do the generic elements form a helpful framework to compare the different architectural design approaches in relation to an underlying design process? To answer the key question four sub questions are to be answered: (1) Do professional designers recognize the generic elements in their design process and if so, which notions do they use? (2) How do they describe and interpret the elements; which features do they point out? (3) What are personal differences in each element? (4) Do they have comments on the framework as a whole?

\section{Method: designers interviewed}

The main criterion, applied in the selection of participants, was to form a group of interviewees that represent a wide variety of personal "designerly" ${ }^{1}$ approaches. Therefore, participants were selected because of the different content of their design work, which in some cases led to publication and discussion. Other aspects in the selection such as the extent of their involvement in different educational institutes and their different educational backgrounds (see Table 1) also played a role. The group includes both unknown and known designers. They were born between 1948 and 1970, mostly in the Netherlands, except for two, who were born in Italy and Portugal. The designers interviewed are architects $(n=11)$, urban designers $(n=2)$ and landscape architects $(n=2)$. The interviewees all work in the design practice. Many worked in different offices and they all had their own office at the time of the interview.

The interviews were semi-structured. To decrease the risk of prejudice, the focus was on the designers' stories. The elements were used as starting points for talking about the personal design process. For each element the main question was: "Do you recognize and can you tell about this element in your approach?"

Other questions arose in the context of the designer's story, to stimulate further clarification of particular aspects and to encourage further talking, all with an open mind to critique on the framework.

The interviews started with a short overall introduction (approximately 5 to $10 \mathrm{~min}$ ), including the explanation of each element. Four out of the fifteen interviewees already knew or had read about the framework, but the others heard about it for the first time. The participants were interviewed by one interviewer (ED, the first author) for approximately $1 \mathrm{~h}$. The interviews took place in 2013 and 2014 in the Faculty of Architecture in Delft or in the designer's office. All interviews were in Dutch, except for one, which was conducted in English.

\footnotetext{
${ }^{1}$ Cross (2007). Designerly ways of knowing. Basel, Boston, Berlin: Birkhauser.
} 
Table 1 Education and involvement in education per interviewee

\begin{tabular}{|c|c|c|}
\hline Designer & Education & Tutor/lecturer \\
\hline 1 & $\begin{array}{l}\text { Faculty of Architecture Porto and } \\
\text { Faculty of Architecture TU Delft }\end{array}$ & $\begin{array}{l}\text { University Montevideo, Porto, TU Delft, ArtEZ in } \\
\text { Arnhem and Zwolle, Academy of Architecture } \\
\text { Amsterdam, Rotterdam and Groningen }\end{array}$ \\
\hline 2 & Academy of Architecture Groningen & $\begin{array}{l}\text { Academy of Architecture Groningen, TU Delft } \\
\text { Faculty of Architecture }\end{array}$ \\
\hline 3 & Faculty of Architecture TU Eindhoven & TU Delft Faculty of Architecture \\
\hline 4 & $\begin{array}{l}\text { Politecnico di Milano, Faculty of } \\
\text { Architecture }\end{array}$ & $\begin{array}{l}\text { TU Delft, Piet Zwart Institute, WDKA Rotterdam and } \\
\text { Politecnico di Torino }\end{array}$ \\
\hline 5 & Faculty of Architecture TU Delft & Faculty of Architecture TU Delft, study year Japan. \\
\hline 6 & $\begin{array}{l}\text { Faculty of Architecture TU Delft and } \\
\text { Academy of Architecture Rotterdam }\end{array}$ & $\begin{array}{l}\text { Interior architecture Academy of Fine Arts The } \\
\text { Hague (KABK) }\end{array}$ \\
\hline 7 & Faculty of Architecture TU Delft & Faculty of Architecture TU Delft \\
\hline 8 & Faculty of Architecture TU Delft & Academy of Architecture Rotterdam \\
\hline 9 & Faculty of Architecture TU Eindhoven & Nijmegen, Architectural academy Amsterdam \\
\hline 10 & $\begin{array}{l}\text { Faculty of Architecture TU Delft, } \\
\text { Universidad Autonoma de Barcelona }\end{array}$ & no teaching \\
\hline 11 & Faculty of Architecture TU Delft & Academy of Architecture, Groningen \\
\hline 12 & Landscape Architecture, Wageningen & $\begin{array}{l}\text { Faculty of Architecture TU Delft, Hogeschool } \\
\text { Utrecht, Wageningen University, Utrecht } \\
\text { University, Academy of Architecture Arnhem }\end{array}$ \\
\hline 13 & Faculty of Architecture TU Delft & TU Delft Faculty of Architecture \\
\hline 14 & $\begin{array}{l}\text { Urban planning and design Faculty of } \\
\text { Architecture, TU Delft }\end{array}$ & $\begin{array}{l}\text { TU Delft Faculty of Architecture. Active in education } \\
\text { at several universities and academies }\end{array}$ \\
\hline 15 & Landscape Architecture, Wageningen & $\begin{array}{l}\text { Academy of architecture, Amsterdam. University of } \\
\text { Berkeley }\end{array}$ \\
\hline
\end{tabular}

The interviews were recorded and verbatim transcriptions were made. The interviews were analysed in two ways: summarizing and labelling. Going deeply into the transcriptions, making, reading and rereading them, helped explore the essence and capture it in a summary, directed by the five generic elements. The designers received the summaries of their interviews and were asked to confirm the adequateness of the interpretation.

Also the transcriptions were labelled (in Atlas TI) by two persons. The process of labelling was done separately and in discussion to come up with a reliable result. In relation to the research questions the labelling focused on (1) synonyms and descriptions, the personal notions and ways designers use to describe the activities, referred to with the elements, (2) aspects or features of the architectural design process, in particular the elements, (3) differences in approach between designers and (4) extra remarks, regarding the framework of the elements.

\section{Results}

The way in which the interviewees talked about their way of working differed. Almost all designers talked about their design process, guided by the 5 generic elements. On top of that, one designer showed his design process in detail in one project he had documented. Sometimes designers referred to examples of their own work. One designer talked from the 
perspective of his education studio. The interview with one designer included and followed on a lecture given about the personal design process. The degree in which the interviewees stayed close to the elements, differed from quite close to telling their own story. Nine out of the 15 designers agreed on the summary they received for comments, the other six did not react.

The data of the interviews will be described from the perspective of the 5 generic elements. For each element the results will be given, following three of the sub-questions: (1) the recognition of the element and the notions used, (2) features and further specifications of the element, (3) personal differences. Finally, remarks of the interviewees on the framework as a whole are given (sub question 4).

\section{Experimenting}

Using their own words and notions to talk about the process of experimenting, all designers recognize the experimental character of designing. They call it a process of trial-and-error, of analysing and evaluating different options, of constantly elaborating and changing different options within different scales: "something isn't right in your opinion as a designer; so you change it, you try something else". It is a process of "learning about the project by exploring alternatives and elaborating further".

Sometimes a designer has a more specific meaning for the notions used in the framework. For example, designer 1 makes a difference between testing and experimenting, respectively testing common solutions and developing new languages. In the framework both are included in the element of experimenting.

Together the interviewees come up with several features of the process of experimenting. It is a process of zooming in and out, working on all scales, on a lot of aspects (domains) and at the same time keeping a helicopter view of the work. Experimenting is a lot of work, it is working intensively and concentrated, making a lot of experiments, which often seemed to be put aside again. However, designers point out that all the hard work contributes to the final result. Within the process of experimenting, it is a matter of finding direction (guiding theme). Designers see experimenting as a process of reducing or abstracting, of returning to the essence. Designer 3 emphasises that "thinking it over and over again, you may come up with a simple and intelligent design". Experimenting implies also having confidence in yourself and the process. According to designer 14 experimenting is a process of "jumping in a pool of uncertainties, of endless, often equivalent, possibilities and solutions. You have to be confident that by jumping in, you will find the direction to climb out in the end". Experienced designers point out that they often know what issues they have to solve immediately and what they can postpone. In the words of designer 2 "It also means solving things, not going around the problems. It is about drawing a plan and, when a difficulty arises, immediately testing if it can be solved. By experience you learn to recognize the problems. When you postpone dealing with a problem, there is a risk that you will have to change the whole design." The process of experimenting is a process of doing basic work on the one hand and on the other hand being open-minded and taking nothing for granted. Designer 11 emphasizes that for the larger part it is doing a lot of basic, "known" work. And designers emphasize designing being "in the first place exploring without prejudices" (2) and "It is important to keep in mind that nothing is given information" (4) and "trying to go beyond what we know" (3). The process of experimenting is both a process of being on your own and of working together, of concentration and of associating with co-workers. Two designers $(2,5)$ use various options also in their conversation with the client, to learn about the preferences of 
the client. In this way they trigger the client to find out what he wants and to form an opinion. And designer 6 sees the projects he designed also as experiments, objects of research to learn from for future projects.

The personal differences in the way designers experiment do not seem very large. In fact it seems there are only small differences in the emphasis on the aspects mentioned above. However, two aspects are more outspoken. First, designers' emphasis in regard to the process of collecting and analysing information about task and site varies from being a really important issue to being an analytical or an associative action, taking place almost in the margin of the design process. Second, the process of experimenting is carried out either well-structured or rather chaotic. One designer (10) calls it chaotic, however with the notion that "you have to finish each drawing". Another designer (2) works really well structured by questioning top left on the page what it is that he wants to explore. During sketching the focus is on this question and when finished the preliminary conclusion is written down, bottom right.

\section{Guiding theme}

For the guiding theme, that what gives direction to the design process, the palette of names and notions designers use seems to be the most varied. It is named a fascination, a passion, "an expression of something and not just solving problems", a vision, a way of working, exploring the "inner logic" of a project, the point where "the building takes over" and finding direction. It is also called a set of principles, an ideal to achieve, the inner compass, the handwriting, the essence, and the essential quality. It is a matter of reasons and motives in the choices made: "It is about being consistent". In most interviews the designers almost directly understand what is meant by the notion "guiding theme". In a few interviews alternative notions given by the interviewer such as "things you want to achieve with your designs" or "something that gives direction to the process" helped to explain the meaning. That seems to be related to all different notions used and to the more or less complex, plural or even mystical character of the guiding theme.

Designers experience the (working of the) guiding theme in the whole palette from clear to vague. They ascertain: (1): "If you know what kind of end result you want, it tells you how and what you should do to reach this goal" and (4): "I would put it ahead of everything. When considering architecture as an expression of something and not just as solving problems, the guiding theme has to be there" and (14): "It is there, it is an inner compass; you have to find a direction in all endless possibilities and solutions". At the same time designer 14 concludes that the "longing or what it was, we were searching for" becomes clear to him only when the design is almost finished. However, one way or the other, there seems to be something like a guiding theme, something that helps in keeping focus within the complex design process.

Going deeper into the features, the picture emerges that the guiding theme seems to give direction at two "levels" at least (see Fig. 2). One level is having some kind of projecttranscending theme. Designers take position: it is what in their opinion architecture and urban and landscape design is about. Sometimes they are clear about it, it is their fascination in designing. Sometimes they tell about it after some questioning. One designer (15) called it the way he elaborates the design project and his "handwriting, something by which others do recognize that it is my design". The other level is a project related crystallisation point; it emerges from the situation at hand. In most cases it seems to be a spatial diagram, a formal structure or composition. The relation between the two levels can be as complex and plural as the notion or guiding theme itself. One designer (4) describes it 


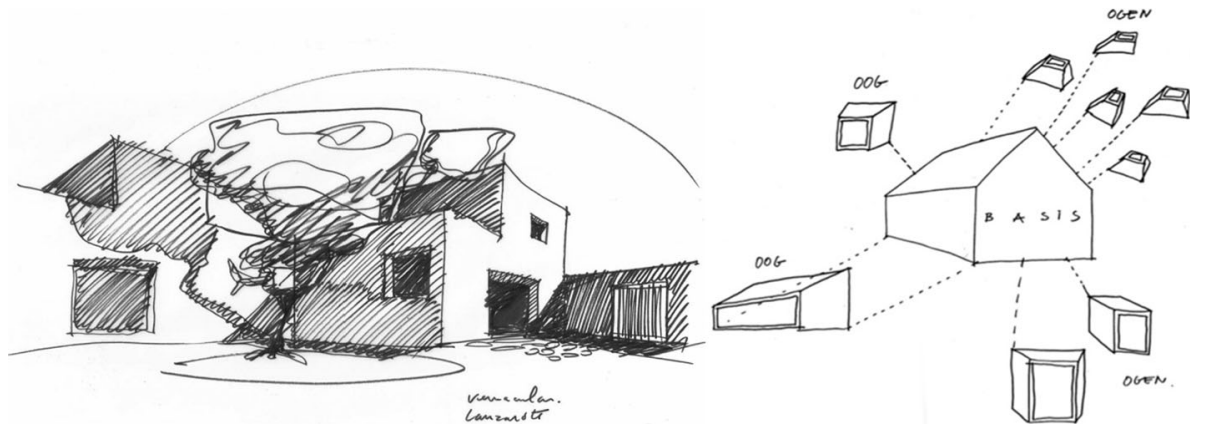

Fig. 2 Example project transcending (light and monolithic) and crystallization guiding theme (monolithic and 'eyes' for light and view) (work designer 1)

as: "It is the form that makes the design coherent. It is like writing a text: you understand the text because there is a relation between the topics. A building that works is a building that has this relation between the parts, the form becomes important at some point as the conclusion of a process. There is a form, that expresses a guiding theme, but probably a guiding theme doesn't express only one guiding form, that's why architects can make 20 different buildings, with the same theme."

The personal differences in the guiding theme seem to play an important role in the design process. An immense rich palette of guiding themes or qualities can be seen (see Table 2). The guiding theme can be a handwriting, a strong fascination, such as for monolithic forms and light, a driving force like closing life circles, a set of guide lines, such as Japanese principles, or principles of ambiguity and balance.

\section{Domains}

In general designers call all aspects and domains they have to attend to by their respective content. They talk about space and form, material, structure and climate, function, urban site, socio-cultural context and all aspects within these domains such as light, texture, colour, energy, composition, and proportions. In principle, domains are related to the design discipline. However, the landscape architects and urban designers recognize the architectural domains. The differences seem to be much more a matter of scale, emphasis and interpretation per design discipline or designer.

Together the designers come up with some features of (working in) the domains. Designers ascertain that they work in and across all domains, they have to make statements and have to decide on all kinds of aspects. Working in the domains is considered a considerable part of the design work: dealing with all aspects and integrate them. One designer (8) compares working within the domains with a "one-armed bandit slot machine": "it is about pulling the trigger, until the moment that all the icons will appear neatly in one row; all the aspects will be in harmony". At the same time, the domains consist of all kinds of aspects a designer has to take into account such as requirements and regulations, criteria, norms, and conditions. You could say that the guiding theme is the main (set of) reason(s). All other criteria, preferences and norms in the domains are of minor importance. Designer 4 describes it this way: "While working on a design you consider several domains at the same time with the guiding theme in the background. At the same time you start with a plot and the plot has regulations: you have to keep distance 
Table 2 Fifteen interviews: fifteen personal guiding themes in the design process

\begin{tabular}{|c|c|}
\hline Designer & Guiding theme \\
\hline 1 & Fascination for the monolithic and daylight \\
\hline 2 & A typological way of working as a kind of rational approach \\
\hline 3 & Inspiration from the socio-cultural, could be everything, e.g. daily habits in a particular culture \\
\hline 4 & $\begin{array}{l}\text { Architecture is a social and political act: a service to people, including topics such as } \\
\text { sustainability and beauty }\end{array}$ \\
\hline 5 & Spatial experience, more specific a fascination with Japan(ese principles) \\
\hline 6 & Life-cycles, to give value to unused potential of different waste flows, such as scrap parts \\
\hline 7 & $\begin{array}{l}\text { Per project: (contrasting) aspects in requirements, client's wishes and site. Sequence of "golden } \\
\text { moments" per project. Up to the point where "the building takes over" }\end{array}$ \\
\hline 8 & Smart technical principles, learning from nature and a spatial concept per project \\
\hline 9 & $\begin{array}{l}\text { Complexity of the urban context; giving cultural meaning to a building within society and } \\
\text { showing important characteristics of an area }\end{array}$ \\
\hline 10 & For each project a vision, expressed in an aquarelle \\
\hline 11 & $\begin{array}{l}\text { Usually the idea of the client or government. And a transcending focus on the way people } \\
\text { interact; the relation between private and public }\end{array}$ \\
\hline 12 & $\begin{array}{l}\text { Coming up with the organising structure out of the qualities/the essence of the landscape, being } \\
\text { strong enough to guide the spatial intervention }\end{array}$ \\
\hline 13 & Abstracting to essence and implicit values such as "democratic urbanism" \\
\hline 14 & $\begin{array}{l}\text { Ambiguity. Balance between what is there and what is changeable, between the broadness and } \\
\text { intimacy/tactility, between past, present and future }\end{array}$ \\
\hline 15 & $\begin{array}{l}\text { Project-related: the essence of the site and question of society, client. Overall handwriting: long } \\
\text { lines, spaciousness and openness, fine detailing, quality material and simplicity }\end{array}$ \\
\hline
\end{tabular}

from the neighbour, from the road, there is noise, there is orientation. Also the historical tradition, the context and the historical context play a part. So all these elements are more practical, they intervene, and they are related to the design. It just happens that you start working with all these elements and you keep your theme in the background."

Personal differences between designers are to be found in the different emphasis on one domain or a combination of domains. Designers may emphasise the urban (12), a combination of urban and socio-cultural context (9), the material domain (4 and 8), the domain of space and form $(1,2,5)$ or a combination of function and urban context (7). The emphasised domains often seem to be related to the guiding theme.

\section{Frame of reference}

Most designers refer to the library or frame of reference with the notion references. It is also called a toolbox and a pattern language. The references could be abstract patterns, principles and rules of thumb, but also actual images, referring to patterns and principles. They could be a personal belief or common cultural principles. A lot of these principles are part of the professional (architectural, urban or landscape design) field, but designers are also inspired by seeing and studying entirely different fields, for example literature, dance, choreography, painting and nature.

Together the interviewees come up with several features of the element "frame of reference". Developing your personal frame of reference is a lifelong process. One designer (8) observes that it may start with the images of your youth, like narrow small 
streets, busy avenues, a centuries-old tree, a theatre. Another designer (14) points out the role of plan analysis during his studies. It is about understanding plans, sites, cities and houses by making plan analyses. Designer 10 ascertains that designers learn from and are inspired by all kinds of ("beautiful") things that they come across in their lives. Visiting buildings and cities is one important way to develop your personal frame of reference, reading books and seeing photographs in newspapers and magazines another. Some designers emphasize the importance of experiencing buildings by visiting and sketching (Fig. 3). One designer (2) said: "After sketching things tend to be better remembered than when documenting a project with photos or film". The designers observe that they often use references unconsciously. One designer (4) says: "Only after I had made a sketch, I realized that it looked like a building that I really liked and which I saw earlier." On a general and a personal level the frame of reference is a dynamic and developing library of knowledge and experience. Working with principles, rules of thumb and images is an open activity: they don't provide a set of fixed rules. Designers use existing principles and patterns and transcend them by finding "new" ones. One designer (8) describes it this way: "It is about using patterns and about creating new patterns. About staying innovative, being curious about new things, finding new solutions".

For a part, the frame of reference consists of all kinds of common, practical and basic professional principles, patterns and rules of thumb. For example, architect 7 not having much specified information about the actual functions in advance, knows that an 8 by $10 \mathrm{~m}$ grid would be suitable for designing flexibility. The urban and landscape designer 14 uses principles and patterns such as the lot measurements and drainage.

For another part, the frame of reference consists of specific principles, patterns and rules of thumb, preferred by an individual designer or a group of designers. Here the personal differences are to be found. Examples of these cultural or personally preferred principles are: (10:) "the beauty is not in making things abstract, but in that which makes it a little bit complex, for example, the dovetail in a wooden box makes the box beautiful; it shows craftsmanship" and (12:) "wanting the landscape design to look as if it hasn't been designed at all". There seems to be a relation between these specific, personal references

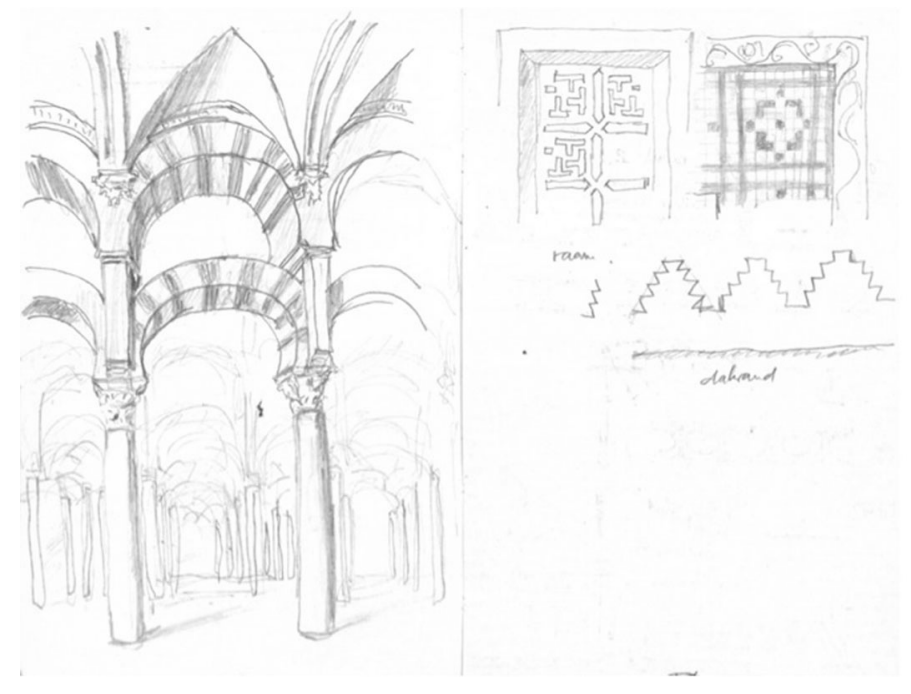

Fig. 3 Sketches excursion to Cordoba Spain (work designer 2) 
and the guiding theme. For example, principles and patterns used by one designer (5) are influenced by his fascination for Japan, where he lived, studied and worked for one year. His experiences in Japan are much more than just a source of inspiration; he calls it his "second nature".

\section{Laboratory}

Designers refer to the laboratory with the elements involved; sketching, modelling, digital drawings, perspectives, and so on. Traditionally designers sketch and make physical models. In a time when the digital possibilities are developing rapidly, designers also work at the computer. However, the traditional means of sketching and modelling are still important. When using the computer, designers often work with programs that at least partly use the features associated with sketching.

When talking about the "laboratory", all designers, except for two, emphasize the role of sketching. They refer to features and qualities, such as working really fast and only needing pencil and paper. One of the designers (4) shows a (sketch) drawing, which he made on a placemat in a restaurant in Venice; it portrays a complete impression of a building: facades, details, perspectives and floor plans (see Fig. 4). Two other designers (9 and 13) made sketches during the interview to express and illustrate what they meant. Also "the direct contact between brain and hand", the "physicality" and "openness" when sketching are mentioned. According to designer 14, it is about sketching "thin" and "thick" lines, "unsure" and "sure" lines in the process of analysing, discovering and trialand-error. Working digitally has its own set of advantages: easy shifting between different

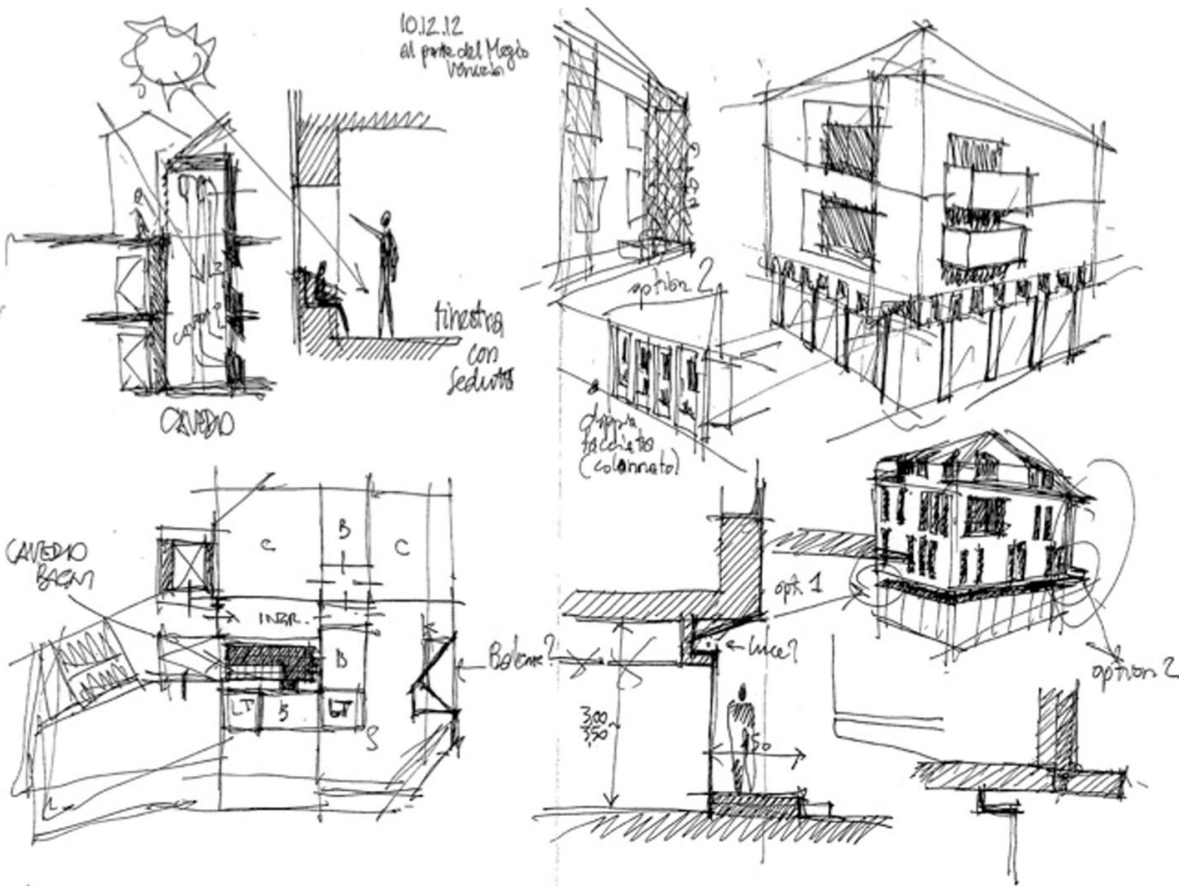

Fig. 4 A project on a placemat; all kind of sketches (work designer 4) 
scales, the possibility to immediately add textures like wood or metal, restrictions and measurements, and the possibility to "walk through" the design to get a better sense of space. The disadvantage of using the computer in the development of a design is that it can be too precise and the loss of direct contact between hand and brain. Sometimes the project at hand asks for a specific medium in the laboratory. One designer (7) used movies to develop an $800 \mathrm{~m}$ long building near the highway to find out what effect the building would have on car drivers. Another designer (1) makes a model in a relatively large scale (scale 1:20) to experience the light in a design.

There seem to be no major personal differences in the way designers sketch, model and work digitally. Almost all designers experiment in sketches. Only two designers find that for them the role of sketching during the design process is minor or even not important at all. One designer (12) mentions the vocabulary also being an important laboratory for designers, besides drawing. He values the cerebral side of designing and sees himself more in the role of a thinking designer. He calls himself a rationalist who needs to develop a repeatable, verifiable line of reasoning. The other designer (11) emphasises that he visualizes the building in his mind in a very early stage. He doesn't need to sketch a lot to know the design.

\section{Framework}

The elements are aspects or activities, distinguished to make them explicit for educational purposes, but interwoven in a complete, integrated whole. The elements are not meant to represent steps in a fixed sequence. The stories of designers confirm and emphasize this.

Four designers made remarks about the choice of the elements. One designer (9) thought it could be four elements - experimenting and laboratory being one element. One designer (11) thought it could be even two - only experimenting and guiding theme-, but he almost immediately concluded that in that case some kind of suborder would be needed within those two. One designer (7), emphasising "analysing" in his design process, missed it as a separate element.

\section{Conclusions and discussion}

\section{Generic elements and differences}

In regard to the first research sub-question, the results show that the elements, as proposed and defined in the framework, can be recognized in the architectural design process of all designers interviewed. They may put different emphasis on what the elements stand for in their personal process, and they may differ in naming them, however, the elements were recognizable, at least to a certain extent. In fact, the spontaneous notions and words used to describe four out of five elements, nor the content didn't seem to differ a lot. Only for the guiding theme, designers use a lot of different synonyms and descriptions. Basically, also these notions seem to mean and refer to the same thing: some kind of constant factor, emerging in and to a certain extent directing the design process. The interviewees experienced differently that what is called in the framework a guiding theme: from a clear personal fascination to a mystical existence.

In regard to the second sub-question, the way designers describe and interpret features and aspects provides a more profound and detailed understanding of the design process and 
more in particular the five defined elements. The most interesting topic in this respect isagain - the guiding theme. From the start of the development of the framework, the guiding theme was referred to as a "train of thoughts" (van Dooren et al. 2014). In the interviews, this seems to be confirmed and, moreover, it became more concrete. At least two important "centres of gravity" can be seen: an overall quality or set of qualities to be achieved by the designer, often project transcending, and a "crystallisation point", often a spatial/formal, structural sketch, specific for the project at hand.

In regard to the third sub-question personal differences can be distinguished. Designers experiment in a well-structured or rather chaotic way, they work often or seldom digitally, and the emphasis is on analysis or association. Yet, these differences seem to be relatively small. They are partly due to personal preferences, partly due to the different nature of projects. Individual differences seem to be most prominent in the guiding theme. With the guiding theme, varying from a more or less conscious choice what qualities to achieve to the experience of the emergence of a continuous factor, a designer takes position and "imposes an order" (Schön 1987) in a particular personal way. At least for a part, directly related to the personal guiding theme is a personal library or frame of reference, a preference for certain principles, patterns and examples and regularly a certain emphasis on one or two domains.

In regard to the fourth sub-question, the elements seem to outline the basic design activities. To a certain extent, the choice of elements may always be a topic for discussion. ${ }^{2}$ At the same time, there might be some logic in the proposed elements, in the context of the criteria (van Dooren et al. 2014): the elements have to be (1) generic, always present, (2) for educational purposes, to explain and train students, and (3) easy to remember, a clear overview.

Finally, in regard to the main research question the results show that the framework makes it possible to see and compare differences in personal views and approaches in relation to the underlying design process. Overall, the impression is that the framework lives up to what it was meant to be: a simple diagram of the underlying, basic, generic design activities, aimed at achieving and keeping an overview of the much more rich and nuanced design reality itself. Interesting in this respect are some spontaneous remarks. One designer (4) considered the framework to be useful to learn about his own design process. Another designer (14) — who, as a teacher, is particularly interested in exploring ways to help students in learning to design-thought the framework to be useful for education.

Looking back at the wide variety of design examples, mentioned at the start of this paper, the framework gives a deeper insight in the differences. In particular, they seem to be expressions of personal interpretations and choices of the guiding theme.

\section{Limitations}

Each research method has its specific strengths and limitations. In summarizing and labelling the interviews, we tried to stay close to what was said. Assuming that what was said, what was meant and what really happened in the designers' way of working are more or less directly related. On the one hand, knowing that an expert practices his or her skills mainly implicitly, a limitation of interviewing is that designers may not be able to tell everything about their design approach. Interviewees differ in their awareness of their way

\footnotetext{
${ }^{2}$ In the end it is a philosophical question if it is possible to have a perfect, all inclusive 'theory' or 'model' or that the best we can do is come up with constructions, matching the phenomena in the best possible way and resulting in different perspectives or views matching the purpose they are constructed for.
} 
of working, in their ability to explain things, in the ways in which they talk about the subject, and in their 'black spots' or biases. Also the situation and the interviewer may influence the course and outcome of the interview. On the other hand, structuring the interviews by the five elements may have helped the interviewees to think of different aspects of the design process, they should have overlooked otherwise. And the fact that the interviewees often accompanied their talking with sketching and showing projects or other examples, helped to make implicit knowledge explicit.

Having an overview of the interviews, it became apparent that some interviewees had a more subjective way of talking, whereas others were more objective. Some of the designers focused on what they, in contrast to others, saw as 'good' architecture. Other designers focused on facts and features of their way of working. In fact, here we see the difference between positioning yourself within the architectural debate and describing your way of working.

Also the process of analysing and labelling may cause limitations. The process of labelling was directed by the framework of five generic elements and the questions regarding aspects and personal differences, being the main topic of the research. Although the process focused clearly on the research question, there is always a risk that this leads to a tunnel vision. To avoid this, we asked for general remarks or critique on the framework (sub question 4) and tried to stay as open minded as possible.

In the context of this research the conclusion is that interviewing designers in a semistructured way is suitable as a first exploration to see if the framework is useful in mapping similarities and differences. During the interviews, the primary focus was on discovering if and in what way all the elements of the framework were recognized. Next to that, learning about the features and about new details and connections was also aimed at. The interviews ended at the point where no new information seemed to come up. However, then new questions emerged. These may be answered by research with a different approach: structured questioning and observation. For example, an interesting topic is the relation between on the one hand being open-minded, taking nothing for granted and on the other hand doing a lot of basic, familiar work. In the interviews the former is mentioned 4 times and the latter only 1 . This seems to correspond with design education where teachers often emphasize the importance of being open-minded and "forget" to tell about the basic, familiar work. Designers may be less aware of the role of this topic in their design process. Also interesting in the context of design education would be to have more detailed examples of the elements. Observing designers at work will give a more concrete and detailed insight in their way of working. It should clarify the design process and bridge the gap between the abstract and the concrete level.

\section{Implications for design education}

The interviews show and confirm what may to a certain extent be called a Babylonian confusion of tongues; everybody speaking a different language, from different perspectives and with different ideas about the "right" approach, but in the end about the same content, about "building the tower". In the debate and the architectural practice, it may be the way designers show their uniqueness, in design education it seems to be a gap, for students a source of confusion.

Having a first confirmation that designers recognize the elements and that the framework may help in showing differences in personal approaches in relation to underlying basic design activities, naturally, besides doing more research in this respect, the next question is whether and how the framework may be used in design education. 
First, the framework may help in creating a common educational "language" about the design process. By using the same notions for the most important design activities or at least relating various notions with each other, the Babylonian confusion may be reduced. Regarding the second perspective in design education models mentioned above in the Introduction, the framework of generic elements makes use of and summarises what researchers have found out about the cognitive aspects of the design process. In a particular way it combines both directions: the framework is grounded in designing as a reflective practice, but it does not exclude aspects of rational problem solving.

Designers all have their own way of talking about the design process. Parallel to that, in their role of teachers they don't seem to be used at all to talk about the design process. Personal observations in design classes suggest that most of the time they seem to talk with students about 'product aspects', such as light, spatial experience, the proportion of space or mass and technique. The framework offers teachers and students in architecture a vocabulary to make the underlying design process more explicit.

Some examples will illustrate this. Teachers could and should explain more than once that designing is a matter of experimenting. Designing is a matter of questioning yourself "what if I do this?". It is a matter of coming up with alternative solutions and possibilities, reflection and decision making. It may be structured or unstructured. Opening one's mind for different solutions prevents a designer from getting stuck, helps learning about the design task and improves the quality of the design at hand. Teachers should also explain that experimenting is also for expert designers in most cases only possible by sketching and making 'quick' models. The laboratory functions as an extended memory to store all kinds of information and is necessary to discover (unexpected) implications of experimental solutions. Teachers' explanations could be accompanied by visuals. Not in a perfectly expert way, but simply by showing the students how they themselves have to experiment and sketch to find out what happens, what kind of implications (and surprises) may come up, what they see in a sketch and what they think of it. By doing so, they may illustrate what Schön (1987) calls a 'conversation with the situation' and 'reflection-in-action'.

In relation to the stages students go through from novice to master (Dreyfus and Dreyfus 1986; Lawson and Dorst 2009), the way in which the vocabulary could be used, may differ per stage. For example, for novices experimenting and choosing a guiding theme may be a straightforward matter, 'applying the rules'. In later stages, experimenting and working with guiding themes may be more nuanced, complex and related to the situation at hand. Then all kinds of different aspects of the elements could be involved, such as finding your personal guiding theme or ethical aspects.

Furthermore, regarding the third perspective in design education models mentioned above, the framework could also be used within the context of the educational process, by making implicit activities in the process of learning-by-doing explicit. It may help teachers in coming up with learning goals, assessment criteria and design tasks. It should help teachers make explicit which activities students should train with greater focus to internalize 'thinking designerly'. For example: sending students home with a design assignment 'to work on' or telling them to 'think out of the box' is a far cry from asking them to come up with a number of alternative ideas or to explore and experiment with different solutions and reflect on them. Examples of process oriented learning goals are: 'being able to come up with different ideas and solutions and reflect on them', 'being able to translate a vision or idea in a concrete, project related (spatial) scheme' and 'being able to reduce and abstract all kinds of information into the essence'.

Secondly, in particular in the context of this paper, the framework may then also work as an anchor point, from which you can recognize and show different approaches. 
Regarding the first of the three perspectives in design education models mentioned above, in a multiform society the framework is meant to go beyond the cultural and personal differences in method or approach and make them explicit to students-(1) to achieve an overview of the architectural debate and all kinds of positions in it, (2) to compare them and understand all kinds of similarities and (personal) differences, and (3) as a result, to be better equipped to develop a personal approach.

Differences in approach related to the design task at hand, could and should be explained, discussed and compared. For example, working chaotically or structured, and the balance between associative thinking and analysing, are important issues within the element of experimenting. Making these differences explicit is (again) a matter of explaining in combination with experiencing them. Students should not only follow implicitly a design teacher in his or her way of designing, but should also explicitly practice different ways of working in design tasks. For example, it may be helpful for students to be told about and experience explicitly the differences between sketching-byhand and computer modelling and the effect they have on the outcomes of their design processes. This may improve their ability to select the most adequate way of working for the design at hand.

Apart from such smaller differences, the development of a personal view on architecture is an important issue. Students often experience confusion because teachers-being expert designers - talk about architecture from their personal angle. For example, one designer (8) considers architecture as creating a place with identity, to make the city richer, whereas another designer (9) considers architecture as using technique in a smart way and a third one (1) considers architecture as sculpturing and playing with light. With the framework, designers (read teachers) might be able to position themselves. This may help in distinguishing talking about the generic design process and showing the personal design process as an illustration. It may help separating discussions on 'what is good architecture' from practicing generic activities. And it may help guiding students to explore their personal way of working. Students may develop a greater ability for 'naming and framing' (Schön 1983, 1987) and for positioning the different personal visions of designers and teachers in particular. By understanding and experiencing differences, they may be able to develop their own preferences in vision and approach.

In fact, in making explicit the design process, there could and should be an interesting role for what in the framework is called the guiding theme. In showing the differences in the personal design approaches, in coming up with all kinds of personal influences, the framework transcends the 'technical rational' description of common design process activities (see the second perspective in design education models mentioned above in the Introduction). The framework provides in 'objective' similarities and the open palette of 'personal' perspectives in designing the future. Here, also the door may be opened for cultural and ethical discussion as well.

With the choice of a guiding theme-being a lifelong fascination or a fascination in the context of a project-a designer takes position. Here the personal may be the most expressive. Bielefeld and El Khouli describe it this way: "Every design begins with a search for an idea or for an intuitive understanding of how an assignment should be solved. This idea is the start of a long journey on which the designer defines the idea more precisely, modifies it, adds details and repeatedly rejects results" (2007, p. 7). "This design perspective is often directly related to the designers' character, and is not limited to interaction with architecture. It can be an expression of an entirely personal worldview and associated with a broader social context or philosophy, developing a design perspective is this part of an individual maturation process and cannot be forced or artificially produced" 
(2007, p. 14). It might be helpful for students and teachers to focus as explicitly as possible on these aspects, both in the process of learning-by-doing in the studio and in lectures and other information sources around the studio. A "philosophy of the guiding theme" should be at least concerned with (1) the particular aspects of (working with) a guiding theme, also in relation to the other elements, and (2) its character, which means an almost endless number of differences in cultural and personal views and ideas.

Moreover, a "philosophy of the guiding theme" is an example of bridging the gap between theory and practice, between courses around the studio and the studio itself. Architectural design education often seems to be (implicitly) grounded in the assumption that courses give information and students have to bridge the gap by themselves. They have to comprehend all kinds of relations between courses and in particular they have to understand how to apply knowledge in practice. Students may get a better picture when the different courses and studios are related to each other. For example, courses about all kinds of knowledge could include rules of thumb and principles and patterns, being the translation between theory and practice, and could show that knowledge provides in possible experiments in designing.

In this paper the focus is on the personal design methods and approaches (of the interviewees) in relation to the underlying generic elements in the design process. However, transcending the personal approaches, cultural tendencies could be recognized in architectural methods as well (see for example, Leupen et al. 1993; Bielefeld and El Khouli 2007; Jormakka 2008). It is expected that cultural tendencies, often described afterwards in historical overviews, might be related to the generic elements as well. A "philosophy of the guiding theme" could be extended with these cultural tendencies. Here, guiding themes, cultural situation, architectural history and ethics may come together. For example, in a course students had to design a piece of furniture with themes that originated from historical pieces of furniture. Teachers concluded that the design process became more focused (being already 'halfway' a guiding theme) and students learned about guiding themes and architectural history also by experience. ${ }^{3}$

To conclude: focusing on architectural design education from the perspective of the design process may add new views and connections. With the introduction of the framework, as a construction or perspective to study the design process and in particular the personal similarities and differences in the way of working of architectural designers, the emphasis on information that used to be implicit will give rise to a new understanding and experience but also to new questions. It is to be hoped that teachers and students will be triggered to talk more explicitly about their own and others design process, that they will learn about it and will develop a greater ability to define their personal position.

Acknowledgement A lot of thanks to all designers for making time and for making the interviews a fascinating journey through the design process!

Open Access This article is distributed under the terms of the Creative Commons Attribution 4.0 International License (http://creativecommons.org/licenses/by/4.0/), which permits unrestricted use, distribution, and reproduction in any medium, provided you give appropriate credit to the original author(s) and the source, provide a link to the Creative Commons license, and indicate if changes were made.

${ }^{3}$ Charlotte van Wijk and Elise van Dooren, TU Delft. 


\section{References}

Bielefeld, B., \& El Khouli, S. (2007). Design ideas. Basel: Birkhauser Verlag AG.

Cross, N. (2001). Design cognition; results from protocol and other empirical studies on design activity. In C. Eastman, M. Newstetter, \& M. McCracken (Eds.), Design knowing and learning: Cognition in design education (pp. 79-104). Oxford: Elsevier Science.

Cross, N. G. (2007). Designerly ways of knowing. Basel, Boston: Birkhauser.

Darke, J. (1979). The primary generator and the design process. Design Studies, 1(1), 36-44.

Dreyfus, H. L., \& Dreyfus, S. E. (1986). Mind over machine, the power of human intuition and expertise in the era of the computer. New York: Free Press.

Hillier, B., Musgrove, J. \& O'Sullivan, P. (1972). Knowledge and design. In Environmental design: research and practice EDRA 3 Conference. Los Angelos: University of California.

Jormakka, K. (2008). Basics design methods. Basel: Birkhauser Verlag AG.

Lawson, B. (1994). Design in mind. Oxford: Architectural Press.

Lawson, B. (2006). How designers think, the design process demystified. Amsterdam: Architectural Press. Lawson, B., \& Dorst, K. (2009). Design expertise. Oxford: Architectural Press.

Leupen, B., Grafe, Ch., Ch, N., Lampe, M., \& de Zeeuw, P. (1993). Ontwerp en analyse. Rotterdam: Uitgeverij 010.

Schön, D.A. (1983). The reflective practitioner: How professionals think in action. New York: Basic books.

Schön, D. A. (1987). Educating the reflective practitioner: Toward a new design for teaching and learning in the professions. San Francisco: Jossey-Bass.

van Dooren, E., Asselbergs, T., Boshuizen, E., van Merrienboer, J., \& van Dorst, M. (2014). Making explicit in design education: generic elements in the design process. International Journal of Technology and Design Education, 24(1), 53-71. 